\title{
Advanced engines for non-conventional kinematic chains in agriculture
}

\author{
F. Kh. Khaliullin*, K. A. Khafizov, R. A. Usenkov, and R. A. Latypov
}

Kazan State Agrarian University, 420015 Kazan, Russia

\begin{abstract}
To intensify agricultural production in the market environment, it is necessary to reconstruct the whole economic mechanism considering energy efficiency. This calls for the search of new ideas for alternative designs and engine types that can raise the performance of heat engines to a new level while keeping their use in vehicles, machinery, and small energy facilities feasible. One of the options is the displaced shaft rotary engine. This article analyses the kinematic and dynamic metrics of the engines of this type and presents the calculations of these metrics for the prototype. Key advantages and disadvantages of this type of engine in terms of working process dynamics are set out. It is also compared to the reciprocal internal combustion engine of the same structural dimensions.
\end{abstract}

\section{Introduction}

Agriculture in Russia has large reserves for its development and operation. In the context of the market economy, it implies the reconstruction of economic relations considering energy efficiency. The efficiency of the industry can be significantly increased by organizing the production based on the principles of resource and power saving. While solving resourcesaving problems, it is necessary to adopt innovative development methods. Resource-saving itself must be modernized using innovative approaches $[1,2]$.

The volume of materials and resources used in crop farming every year exceeds 400 billion rubles. The largest costs are incurred through the engineering and utility branch of agribusiness, whose proportion in the prime cost of the agricultural produce is between 60 and $65 \%$ [3]. That being said, about $50 \%$ of engineering and utility costs in agribusiness are incurred due to the purchase of fuel and lubricants.

The key reasons for high energy consumption and low energy efficiency in agricultural production include the lack of modern equipment that is highly productive, efficient, and reliable (less than $3-5 \%$ available), as well as high and constantly growing prices for fuel and lubricants.

That is why the transition of machine and tractor fleet of agricultural companies to more economical alternatives in terms of energy consumption and fuel types is a key objective of agrisciences [4].

Among the most promising fuel types in the short term are the liquefied petroleum gas and the natural gas. They get more and more often used in the automobile industry. There are designs for almost all Russian-made tractors that would allow them to run on gas fuel. The practical use of such tractors (as well as trucks) in agricultural production is, however, limited due to the high costs associated with the arrangement of gas fuelling stations [5].

The use of crop farming wastes as fuel for internal combustion engines appears a real option in the near future. This requires research into the capacities various crop farming waste types have, the methods of their treatment, the best ICE, and power plant flow chart conversion methods.

The possibility of conversion of the diesel and sparkignited engines to use gas vehicle fuel also seems interesting. The analysis and the calculations made show that the conversion of a diesel engine into a pure producer gas engine requires too much design rethinking. Besides, after the transition to a gas and diesel cycle, the fuel shift may only amount to $30-40 \%$ depending on the operating mode if we want to avoid the unacceptable decrease of engine performance [5].

Some works [6, 7] focus on the use of other kinematic chains to create more efficient engines. One of the alternatives is the use of rotary piston engines (RPE) with displaced shafts.

The renewed interest of the scientific community to them is caused by a number of advantages that freepiston heat engines have as compared to the conventional engines that transfer caloric power from the piston to the crankshaft via the crank gear. In particular, the free piston ICEs exceed their crank gear alternatives in material consumption, fabricability, and prime cost, as well as weight and dimensions, operating life, specific efficient fuel consumption, the lower requirements to the fuel used, and hazardous emissions level [8].

All these advantages are mainly explained by the higher net efficiency of such engines achieved through lower friction losses, simple design, potentially better

\footnotetext{
Corresponding author: khaliullin_kgau_taeu@mail.ru
} 
engine balance, and the possibility to adjust the compression rate.

The use of the classic combined lubrication system typical of four-stroke engines is more complicated in free-piston engines due to the presence of valves in the working area of compression and oil rings (in some of the engines), which requires special attention to the development of lubrication systems. One of the most promising technical solutions of today is the use of both the low performance combined lubrication system and solid films applied to the friction parts which improved the economic, environmental, and operating life indices of ICEs $[9,10]$.

When developing power plants using free-piston ICEs, it is crucial to design the cooling system for engine parts because these engines have higher heat release rates and values as compared to conventional ICEs. The situation is compounded by the necessity to reduce the weight of all moving parts in the engine including the actuating pistons to reduce the inertia load, which sets out increased requirements to head abstraction from the heating parts, especially if we take into consideration the increased heat load density of two-stroke engines [11$13]$.

One of the key directions in the development of highly efficient engines using alternative fuels is the creation of rotary piston engines with external heat intake $[14,15]$.

The kinematic chain parameters for autoequidistant rotary piston engine (AED RPE) described in [16, 17], are defined by the processing capacities of the manufacturer and the integrity of the design suggested with a view to the rules and requirements for machinery details and structural bases. The calculation methods and results for kinematic and dynamic parameters of the design without working process parameters are set out in [18] and show its obvious advantage over conventional internal combustion engines.

The goal of this work is to define potential capacities of the engine design suggested along with the possibility of its further use as a source of energy for transport and equipment in agribusiness.

\section{Methods}

The parameters of the proposed design and their impact on the kinematics and the dynamics of the working process are defined following the calculation procedures for rotary piston engines mentioned in $[14,15]$. The comparative analysis of the design under inspection and conventional ICEs was carried out using the relevant algorithms.

The main parameters of an ICE are its power output $N_{e}$, torque $M_{t q}$, and engine shaft speed $n$. Power output is the key parameter determining the capacities and applicability of an engine. Power output, in its turn, depends on two main parameters: engine shaft speed (frequency) and the torque on this shaft. The higher the torque and the shaft speed, the higher the power output. The most efficient method of increasing the power output of an engine is increasing its torque.
In the crank gear of an engine, the torque is the product of the tangential force $T$ of the power gas pressure on the force arm $R$. In a generic form, the $T$ force depends on the total $P$ force (a sum of working gas pressure on the piston and the inertia from reciprocal movements) and the trigonometric dependencies of the crank gear. In the case of rotary piston engines, the arm is between the rotor center and the wobbler shaft axis, and in AED RPE, the arm is between the immediate rotation center and the middle of the working surface of the rotor [18].

\section{Results}

The design diagram of an AED RPE is shown in Figure 1. According to this diagram and assuming that the radii of the output shafts are equal $\left(r_{1}=r_{2}\right)$, their angular velocity values are calculated as radius ratios. Their modulations are shown in Figure 2, where the output shaft speed is calculated using the following formulae:

$$
\begin{aligned}
& n_{1}=\frac{r_{1}}{r} * n_{0} \text { where } \alpha_{1} \leq 60 \text { and } \\
& n_{1}=\frac{r_{1}}{R} * n_{0} \quad 60 \leq \alpha_{1} \leq 120 ; \\
& \text { as well as } n_{2}=\frac{r_{2}}{r} * n_{0} \alpha_{2} \leq 60 \text { and } \\
& \quad n_{2}=\frac{r_{2}}{R} * n_{0} 60 \leq \alpha_{2} \leq 120,
\end{aligned}
$$

where $\alpha_{1}$ is the first output angle, and $\alpha_{2}$ is the second output angle, $n_{0}$ is the rotor speed, $R$ and $r$ are the bigger and the smaller semicircle radii of the working surface of the rotor.

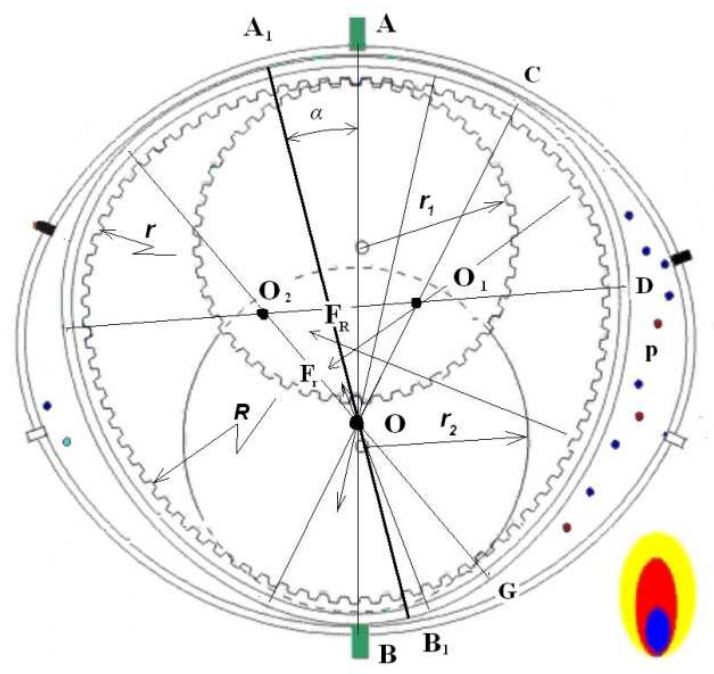

Fig. 1. Design diagram for the autoequidistant rotor piston engine

Here we can see an area of speed jump with the intensity of $\frac{\Delta n}{\Delta \alpha}$, which is caused by the kinematic chain of the design suggested, i.e. the curvature modulation of the internal surface of the rotor from $r$ to $R$. Herewith, the rotation center of the rotor immediately relocates along the axis connecting the rotation centers of the output 
shafts $\mathrm{O}_{1}$ and $\mathrm{O}_{2}$. This phenomenon causes uneven work of output shafts and large inertia loads on teeth joints.

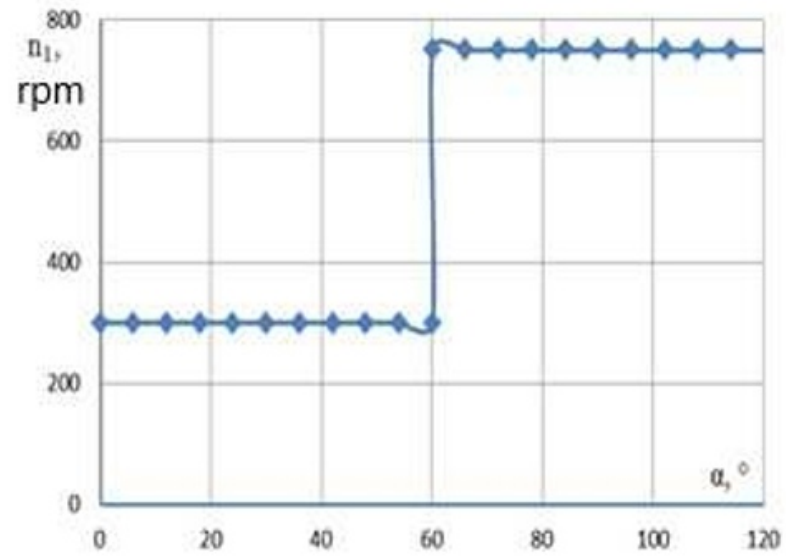

a)

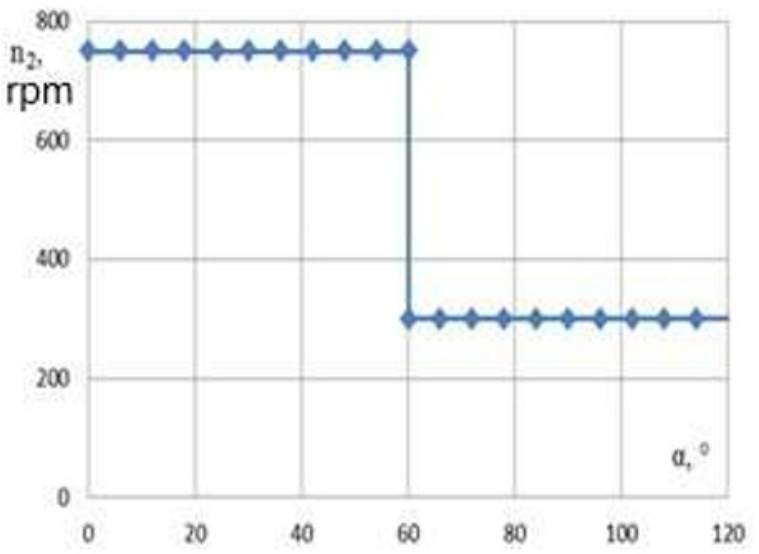

b)

Fig. 2. The turning speed of the first $n_{1}$ (a) and the second $n_{2}$ (b) output shafts

This can be avoided when using continuous curvature surfaces with the radius modulations between $r$ and $R$. Figure 3 shows the output shaft speed modulation graph when using a surface with 3 curvature radii of $r$, $(r+R) / 2$ and $R$ (Figure 3 ).

When using a 5 radii surface, the speed jumps become less sharp, and the inertia loads become acceptable (Figure 4).

We can analyze the correlations between the modulations of the angular velocity of the output shaft when changing from 2 radii to 3 and 5 .

If we assume that

- the angular shaft speed equals $\omega=2 \pi n / 60$ $\mathrm{rad} / \mathrm{s}$;

- sample spacing equals $\Delta t=\Delta \varphi / \omega \mathrm{s}$,

we can get the following expression for angular acceleration: $\varepsilon=\left(\omega_{2}-\omega_{1}\right) / \Delta t \mathrm{rad} / \mathrm{s}^{2}$.

Herewith, the angular range $\Delta \varphi_{i}$ for the use of the following radius $r_{i}$ is crucial because when it changes, the beats of the chosen working cycle of the engine change as well. In our case, we selected $\Delta \varphi_{1}=6^{\circ}$ and $\Delta \varphi_{2}=12^{\circ}$.

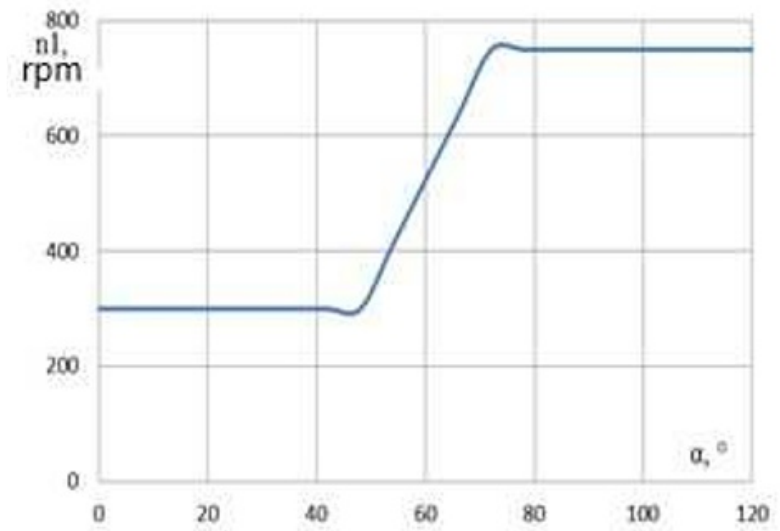

Fig. 3. The modulation of the output shaft speed when using a surface with 3 curvature radii.

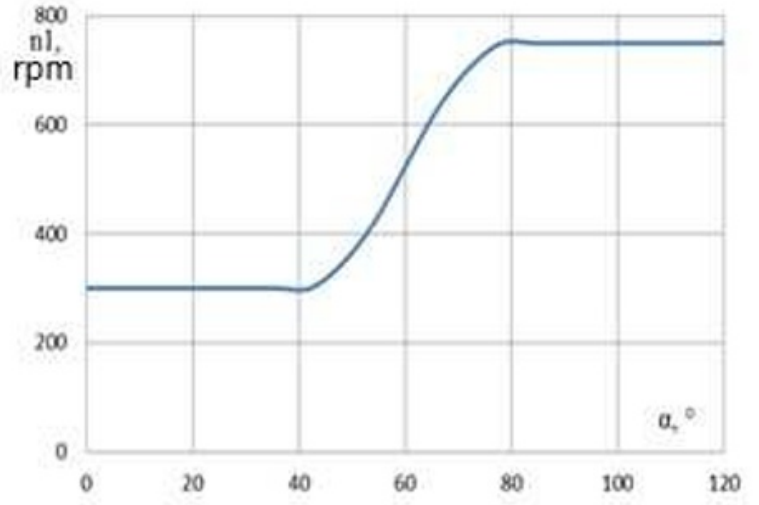

Fig. 4. The modulation of the output shaft speed when using a surface with 5 curvature radii.

The modulations of the angular acceleration of exhaust gases connected to various numbers of radii and their values are shown in Figure 5.

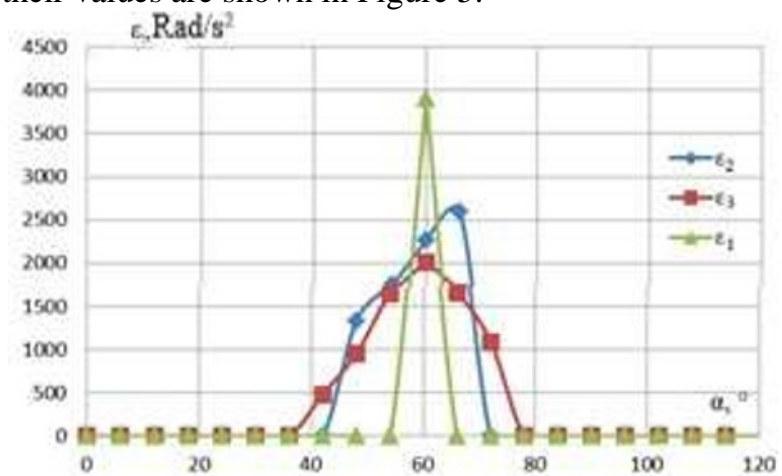

Fig. 5. The modulations of the angular acceleration of the output shaft when using different surfaces: $\varepsilon 1$ - one curvature radius; $\varepsilon_{2}$ - two curvature radii; $\varepsilon_{3}$ - three curvature radii.

The use of a continuous curvature surface allows reducing the maximum angular acceleration values $2.3 \div 3$ times for exhaust gases without adverse impacts on the working cycle parameters.

For the dynamic calculation of the suggested design parameters, it is necessary to know the correlations between the changes in working space pressure and the angular position of the rotor [19-21]. To this end, we 
used a previously calculated Stirling cycle [22] with selected parameters (Figure 6):

- compression rate $\varepsilon=2$, pressure ratio $\lambda=2,2$;

in point 1 (the beginning of isothermic compression):

- pressure $p_{1}=1,7 \cdot 10^{5} \mathrm{~Pa}$;

- absolute temperature $T_{2}=300^{0} \mathrm{~K}$;

- specific volume $v_{1}=0,506 \frac{\mathrm{m}^{3}}{\mathrm{~kg}}$;

in point 2 (the beginning of adiabatic compression): - specific volume

$$
v_{2}=\frac{v_{1}}{\varepsilon}=\frac{0,506}{2}=0,253 \frac{\mathrm{m}^{3}}{\mathrm{~kg}}
$$

in point 3 (the beginning of isothermic expansion):

- specific volume $v_{2}=0,253 \frac{\mathrm{m}^{3}}{\mathrm{~kg}}$;

- pressure

$p_{3}=p_{2} \lambda=3,4 \cdot 10^{5} \cdot 2,2=7,48 \cdot 10^{5} \mathrm{~Pa}$;

- absolute temperature

$T_{1}=\frac{p_{3} v_{2}}{R}=\frac{7,48 \cdot 10^{5}}{287}=659,9^{0} \mathrm{~K}$;

in point 4 (the beginning of adiabatic expansion):

- specific volume equals $v_{1}=0,506 \frac{\mathrm{m}^{3}}{\mathrm{~kg}}$;

- absolute temperature $T_{1}=659,9^{0} \mathrm{~K}$;

- pressure

$p_{4}=\frac{p_{3} v_{2}}{v_{1}}=\frac{7,48 \cdot 10^{5} \cdot 0,506}{0,253}=3,74 \cdot 10^{5} \mathrm{~Pa}$.

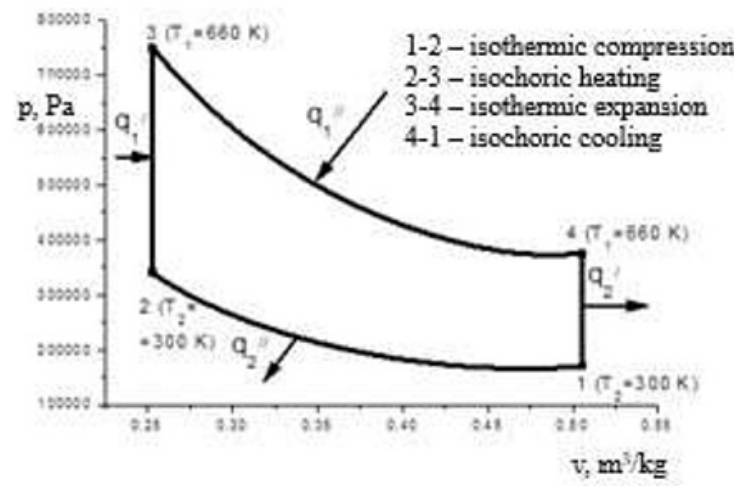

Fig. 6. P-V diagram for AED RPE of the selected design

The effective volume of one chamber is calculating using this expression:

$$
V=H\left(R^{2}-r^{2}\right) 2 \pi / \alpha,
$$

where $\alpha$ is the rotor output angle in radians, $H$ is the rotor width (between the capping end planes).

The torque on output shafts is calculated using this formula:

$$
M_{t q}=p \cdot\left(\operatorname{Vmin}_{\max }\right.
$$

where $p-$ is the actuating gas pressure on relevant points of the cylinder working surface of the rotor limited by the generating lines at C, D, G (Figure 1); $V_{\max }$ and $V_{\min }$ are the maximum and the minimum values of the working volume.

The modulations of gas pressure moment and output shaft torque values in AED RPEs are shown in Figures 7, 8, and 9. The true power of the selected engine according to the work results [9] equals:
$N_{i}=64,7 \mathrm{~kW}$ for a one-chamber and $N_{i}=$ $129,5 \mathrm{~kW}$ for a two-chamber AED RPE.

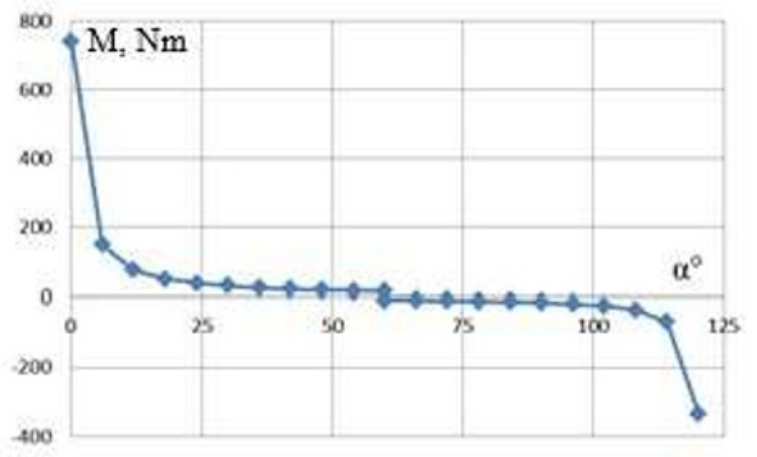

Fig. 7. The modulations of gas pressure moment in chambers of AED PREs depending on the rotor output angle

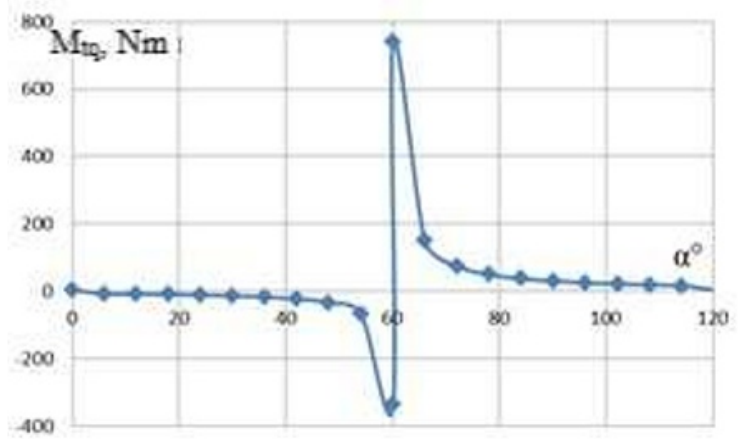

Fig. 8. The modulations of rotor shaft torque when its angle position in one working chamber changes.

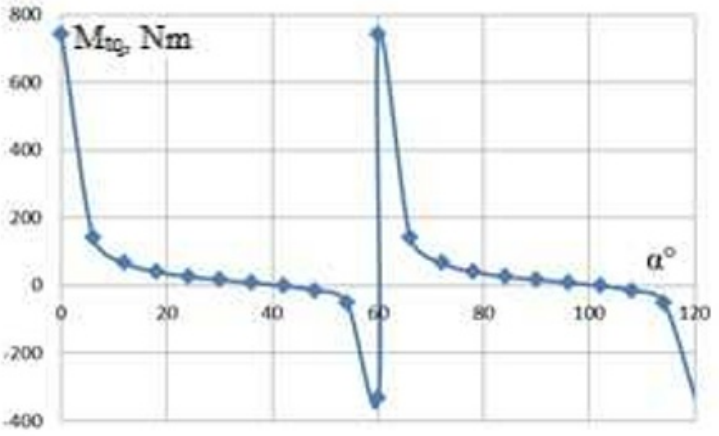

Fig. 9. The modulations of rotor shaft torque when its angle position in two working chambers changes.

\section{Discussion}

The calculations performed to highlight the advantages and disadvantages of the AED RPE design under inspection.

The advantages of the engine design suggested include (for the Stirling cycle):

1. Lower values of inertia forces (as compared to the piston internal combustion engines) due to the absence of reciprocal movements;

2. Higher torque values due to the large surface area of the rotor (as compared to the piston ICE) and a larger arm (as compared to the eccentricity of the piston ICE); 
3. Move even torque distribution (as compared to the piston ICE) due to the smooth of the working gas pressure in the combustion chamber.

The advantages of the design include:

1. The uneven rotation speed of the output shafts and the presence of large inertia forces in the teeth joint contact points;

2. Limited opportunities to install a flywheel to increase the evenness of the engine work due to the increase in the contact loads at higher inertia moment values for rotating parts;

3. Imperfect devices for power transmission from the output shaft (shafts). When using a multi-chamber design, a power combiner is necessary.

\section{Conclusion}

The study of the design developed allowed us to find its advantages and disadvantages. The practical implementation of this project requires the following:

1. To arrange a highly efficient working process, it is desirable to use the Stirling cycle;

2. The use of two-chamber designs improves the evenness of the engine's work;

3. The use of continuous curvature surfaces as operating profiles of the rotor decreases the dynamic loads on the transmission mechanisms;

4. The use of module adjustment principles for cogwheel teeth improves the rotation of gear drives;

5. To exclude the power circulation, it is necessary to use differential drives allowing to combine the torque of the output shafts.

\section{References}

1. S.Yu. Shcheglova, Energy and resource saving in agriculture. Technology review, Proceedings of the IV International Student Scientific Conference "Student Scientific Forum", retrieved from: http://scienceforum.ru/2012/article/2012000560

2. Recommendations on the use of non-conventional energy sources in livestock farming, fodder production, farm households, and rural housing (Federal State Scientific Institution GiproniSelkhoz R\&D Center, Moscow, 2003)

3. A.V. Semyonov, The efficiency of energy resource usage in agricultural production, Izvestiya of Samara State Agrarian University, 2, 37-41 (2013)

4. R.A. Amerkhanov, A.S. Bessarab, B.Kh. Draganov, S.P. Rudobashta, G.G. Shishko, Heat and power plants and agricultural systems (Kolos-Press, Moscow, 2002) 424 p.

5. Yu.T. Chekemes, On the possibility of using alternative fuels in ICEs of agricultural machines, Scientific Journal of KubSAU, 2(18) (2006)

6. F.A. Shustrov, A.P. Tatarnikov, A.S. Nekrasov, The analysis of design solutions aimed at the development of a transport power plant based on a free-piston internal combustion engine, Young
Scientist, 20(124), 231-236 (2016) Retrieved from: https://moluch.ru/archive/124/34301/

7. A.N. Tokarev, G.V. Pyzhankon, Ye.A. Dubov, Comparative characteristics of kinematic chains of internal combustion engines, Polzunovskiy Almanakh, 3(1), 9-13 (2017)

8. N. Khripach, L. Lesnevskiy, M. Lyahovetskiy, A. Troshin, Potential of Microarc Oxidation for Implementation of Dry Friction and Boundary Lubrication Modes in Free-piston Internal Combustion Engines, International Journal of Applied Engineering Research, 10(20), 4095640964 (2015)

9. L.N. Lesnevskiy, L.Yu. Lezhnev, M.A. Lyakhovetskiy, A.E. Troshin, P.V. Gavrilov, A.M. Ushakov, Inorganic Solid Lubricating Coatings for Heat Engines and Power Plants, Journal of Machinery Manufacture and Reliability, 44(5), 455463 (2015)

10. R. Mikalsen, A.P. Roskilly, A Review of Free-Piston Engine History and Applications, Applied Thermal Engineering, 27, 14-15 (2007)

11. N.A. Khripach, D.A. Ivanov, I.A. Papkin, Thermoelectric Cooling System for Internal Combustion Engine Part 2: Experimental Studies. International Journal of Applied Engineering Research, 11(15), 8540-8546 (2016)

12. B.A. Papkin, N.A. Khripach, V.S. Korotkov, D.A. Ivanov, Thermoelectric generator for a vehicle engine cooling system research and development, International Journal of Applied Engineering, 11(15), 8557-8564 (2016)

13. N. Khripach, B. Papkin, V. Korotkov, Thermoelectric generators of motor vehicle powertrains, problems and prospects Life Sci. J., 11(12), 503-507 (2014)

14. V.S. Beniovich, G.D. Apazidi, A.M. Boiko, Rotary piston engines, (Mashinostroyeniye, Moscow, 1968) $151 \mathrm{p}$.

15. G. Walker, Stirling cycle machines (Energiya, Moscow, 1978) $152 \mathrm{p}$.

16. R.A. Latypov, Patent RU No. 2637301 for Rotary Piston Machine (1 December 2017)

17. Ye.V. Shikin, M.M. Frank-Kamenetskiy, Curves in a plane and space. Reference guide with appended Flat Curves disk (FAZIS, Moscow, 1997) 336 p.

18. A.F. Ravich, S.N. Bogdanov, The autoequidistant rotary piston device, Engine, 4(94), 34-36 (2014)

19. W.W. Pulkrabek, Engineering Fundamentals of the Internal Combustion Engine (New Jersey, 2000)

20. G. Blair, Design and Simulation of Four-Stroke Engines (Society of Automotive Engineers, Warrendale, PA, 1999)

21. F.Kh. Khaliullin, A.V. Matyashin, R.R. Akhmetzyanov, V.M. Medvedev, M.A. Lushnov, Prospects for using the Bayes algorithm for assessing the technical condition of internal combustion engines, IOP Conference Series: 
Materials Science and Engineering, 635, 012016 DOI:10.1088/1757-899X/635/1/012016

22. C.A. Khafizov, R.A. Usenkov, F.Kh. Khalyullin, R.A. Latypov, The Thermodynamic Calculation of
Offset Shafts Rotary Engine Ideal Cycle with External Heat Supply, International Journal of Mechanical and Production Engineering Research and Development, 9(4), 1109-1116 (2019) 